\title{
Proteksi Keamanan Jaringan Komputer di Sekolah Menengah Kejuran Al-Madani Pontianak
}

\author{
Ryan Permana $^{1 *}$, Dochi Ramadhani ${ }^{2}$, Isnania Lestari ${ }^{3}$ \\ ${ }^{123}$ IKIP PGRI PONTIANAK, Program studi Pendidikan Teknologi Informasi dan Komputer
}

\section{A R T I C L E I N F O}

Article history:

Received 19 January 2019

Received in revised form

10 February 2019

Accepted 12 March 2019

Available online 25 April

2019

\section{Kata Kunci:}

Jaringan Komputer, Proteksi Keamanan

Keywords:

Computer Networks,

Security Protection

\begin{abstract}
A B S T R A K
Jaringan komputer berkembang sangatlah pesat. Akses terhadap jaringan komputer terutama internet merupakan kebutuhan yang tidak dapat dihindari. Saat ini, internet tidak hanya digunakan oleh individu, tetapi oleh instansi, organisasi, perguruan tinggi ataupun lembaga pemerintah atau non pemerintah. Karna kebutuhan akses jaringan komputer yang tinggi, maka dibutuhkan keamanan jaringan yang memadai. Keamanan jaringan komputer adalah proses untuk mencegah dan mengidentifikasi penggunaan yang tidak sah dari jaringan komputer. tujuannya adalah untuk mengantisipasi ancaman baik fisik maupun logik yang dapat menganggu aktifitas atau data yang ada dalam sistem yang terdapat dalam jaringan komputer. penelitian ini merupakan penelitian kualitatif deskriptif dengan teknik pengumpulan dan penyusunan data dengan teknik triangulasi. Berdasarkan hasil penelitian, ruangan kepala sekolah dan staff tata usaha di SMK ALMadani Pontianak telah memiliki jaringan komputer. proteksi keamanan jaringan komputer yang trdapat dalam ruangan tersebut menggunakan antivirus. Selain itu terdapat mikrotik yang digunakan untuk memblok dan juga membatasi beberapa situs yang diatur dan dikendalikan sesuai pihak sekolah.
\end{abstract}

A B S T R A C T

Computer networks are developing very rapidly. Access to computer networks, especially the internet, is an unavoidable need. Today, the internet is not only used by individuals, but by agencies, organizations, universities or government or non-government institutions. Because the need for high computer network access, it requires adequate network security. Computer network security is the process of preventing and identifying unauthorized use of computer networks. the aim is to anticipate both physical and logical threats that can disrupt the activities or data contained in the system contained in a computer network. This research is a descriptive qualitative study with data collection and data collection techniques using triangulation techniques. Based on the results of the study, the principal's room and administrative staff at the AL-Madani Vocational School in Pontianak already had a computer network. computer network security protection that can be found in the room using antivirus. In addition there are microtics that are used to block and also limit some sites that are regulated and controlled according to the school.

\footnotetext{
* Corresponding author.

E-mail addresses: ryanpermana@gmail.com (Ryan Permana)
} 


\section{Pendahuluan}

Informasi pada era ini sudah menjadi sebuah komoditas yang sangat penting. Kemampuan untuk mengakses dan menyediakan informasi secara cepat dan akurat menjadi sangat esensial bagi sebuah organisasi, baik yang berupa organisasi komersial (perusahaan), perguruan tinggi, lembaga pemerintahan, maupun individual. Dengan perkembangan yang pesat di bidang teknologi komputer dan telekomunikasi sekarang, perlu adanya pertimbangan akan bahaya dan kerugian penyalahgunaannnya baik itu dalam layanan jaringan lokal ataupun dalam aplikasi yang berbasis internet.

Jaringan Komputer berkembang dengan sangat pesat, akses terhadap internet sangat dibutuhkan oleh semua kalangan sekarang ini. Interent tidak hanya di akses untuk mencari informasi bagi orang orang yang membutuhkannya, tetapi juga di akses oleh hacker atau cracker. Dengan alasan tertentu mereka melakukan penyusupan yang dapat merugikan para pemilik server dan jaringan komputer. Mereka menggunakan berbagai macam serangan jaringan komputer dengan tools yang dibuat secara mandiri ataupun yang telah ada. Kecanggihan serangan dan tools pada jaringan komputer berbanding terbalik dengan pengetahuan tentang penyusupan pada jaringan komputer (Fadlil., A, Riadi, I, dan Aji, S.; 2017).

Keamanan jaringan komputer adalah proses untuk mencegah dan mengidentifikasi penggunaan yang tidak sah dari jaringan komputer. Tujuan Keamanan jaringan komputer adalah untuk mengantisipasi resiko jaringan komputer berupa bentuk ancaman fisik maupun logik baik langsung ataupun tidak langsung mengganggu aktivitas yang sedang berlangsung dalam jaringan komputer. selain itu, untuk menjaga data pada sistem komputer supaya aman dari berbagai ancaman.

Sekolah Menengah Kejuruan Al-Madani Pontianak telah memiliki sistem jaringan komputer yang terhubung diruang kepala sekolah yang ruang staff Tata Usaha. Namun sistem jaringan komputer tesrbut belum memiliki proteksi keamanan yang dapat melindungi pengguna dari ancaman fisik dan logik. Rancangan keamanan jaringan komputer yang akan dibangun di Sekolah Menengah Kejuruan Al-Madani Pontianak, dimana pada ruangan kepala sekolah dan ruangan tata usaha dapat diproteksi oleh sistem jaringan komputer. Menurut penelitian yang dilakukan oleh Fadlil., A, Riadi, I, dan Aji, S. (2017) yang berjudul "Pengembangan Sistem Pengaman Jaringan Komputer Berdasarkan Analisis Forensik Jaringan" menyatakan bahwa hasil pengujian dan analisis system pengaman jaringan computer dapat dirancang menggunakan bukti forensik jaringan komputer. Dan penyerang tidak akan mampu melakukan serangan pada waktu yang akan datang dengan menggunakan metode yang sama.

\section{Metode}

Penelitian ini dilakukan di Sekolah Menengah Kejuran Al-Madani Pontianak, dengan jenis penelitian kulitatif deskriptif. Subjek penelitian dalam penelitian ini adalah kepala sekolah dan staff tata usaha di Sekolah Menengah Kejuran Al-Madani Pontianak. jenis data yang digunakan dalam penelitian ini adalah data kualitatif. Sedangkan sumber data yang digunakan adalah data primer yang berasal dari guru dan staff tata usaha dari seolah tersebut, dan data sekunder yang diperoleh dari observasi langsung kepada pihak yang terkait.

Teknik pengumpulan data yang digunakan adalah dengan cara observasi yang gdilakukan kepada guru dan staff tata usaha di Sekolah Menengah Kejuruan Al-Madani Pontianak. teknik analisis yang di gunakan dalam penelitian ini adalah analisis deskriptif. Pengumpulan dan penyusunan data melalui observasi dan wawancara ini dilakukan dengan menggunakan teknik triangulasi. Menurut Priyono dalam Basrowi dan Suswandi (2008:123) triangulasi merupakan proses memastikan sesuatu dari berbagai sudut pandang. Dalam penelitian ini, triangulasi digunakan untuk mendapatkan keakuratan data menggunakan berbagai cara, prosedur, dan metode agar data yang diperoleh dapat dipercaya kebenarannya. Beberapa macam triangulasi yang digunakan dalam penelitian ini adalah: data triangulation dan situational triangulation (Basrowi dan Suswandi, 2008:123)

\section{Hasil dan pembahasan}

SMK Al-Madani Pontianak merupakan sekolah kejuruan yang memiliki beberapa ruangan seperti ruang kepala sekolah, ruang wakil kepala sekolah, ruang tata usaha, ruang guru, ruang kelas, dan laboratorium komputer. Hasil wawancara di SMK Al-Madani Pontianak menyatakan bahwa jaringan komputer penting untuk di implementasikan di sekolah, karena jaringan komputer dapat mengintegerasikan seluruh komputer yang terdapat di sekolah. Subyek wawancara juga menyatakan bahwa dengan adanya jaringan komputer dapat mempermudah pekerjaan yang dilakukan karena data 
sudah teintegerasi dengan baik. Dengan adanya jaringan komputer, pengecekkan secara realtime data dapat dilakukan mudah oleh kepala sekolah tanpa harus bertemu langsung dengan para guru dan staff.

Hasil wawancara menyatakan bahwa ruang kepala sekolah, ruang wakil kepala sekolah, dan ruang tata usaha sudah terhubung menggunakan jaringan komputer. Sehingga ruang kepala sekolah, ruang wakil kepala sekolah, dan ruang tata usaha dapat dengan mudah menyebakan informasi dan data. Jaringan komputer yang digunakan oleh ruang kepala sekolah, ruang wakil kepala sekolah, dan ruang tata usaha merupakan jaringan nirkabel. Sehingga kepala sekolah, wakil kepala sekolah, dan staff TU dapat menggunakan komputer/laptop pribadi. Adapun tugas dari kepala sekolah, wakil kepala sekolah, dan tata usaha adalah sebagai berikut:

1. Kepala sekolah

a) Menetapkan prosedur kegiatan sekolah

b) Memimpin rapat guru

c) Mengkoordinasikan dan menjalankan pertanggungjawaban kurikulum

d) Menyusun perencanaan program kegiatan

e) Melakukan pengewasan proses belajar mengajar

f) Menyelenggarakan suvervisi

2. Wakil Kepala Sekolah

a) Membuat perencanaan kurikulum

b) Membuat laporan pertanggungjawaban kompetensi dasar kepada kepala sekolah

c) Mengkoordinasikan dan menjalankan kurikulum

d) Membantu kepala sekolah dalam kegiatan penyusunan perencanaan

e) Pengembangan keunggulan

f) Identifikasi dan pengumpulan data

3. Tata Usaha

a) Penyusunan program kerja tata usaha

b) Mengurus administrasi guru, tenaga kerja, dan siswa

c) Penyusunan dan penyajian data statistic sekolah

d) Penyususnan laporan pelaksaan kehiatan pengurusan tata usaha secara berkala

e) Penyusunan administrasi perlengkapan

Berdasarkan hasil observasi yang dilakukan di SMK Al-Madani Pontianak. Skema jaringan yang saling terhubung yaitu ruangan Kepala Sekolah, ruangan Wakil Kepala Sekolah, dan ruangan Tata Uaha. Dalam skema tersebut menggunakan topologi Star yang berpusat pada Laboratorium Komputer. Berikut skema diagram jaringannya:

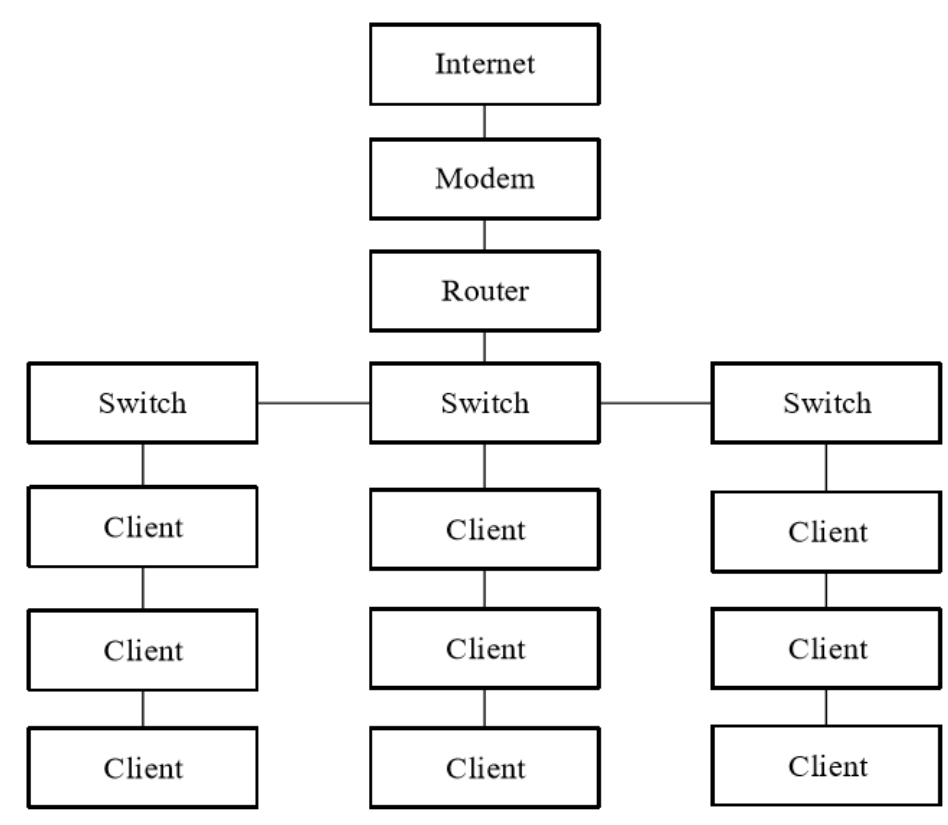

Gambar 1. Skema Diagram Jaringan 
Berikut keterangan dari skema jaringan di SMK Al-Madani Pontianak:

1. Internet: meruparakan jaringan inti dalam skema ini yang dapat menghubungkan lebih dari 2 komputer. SMK Al-Madani Pontianak berlanggan dengan IndieHome untuk dapat berkomunikasi dengan jarak yang jauh.

2. Modem: merupakan suatu alat yang digunakan untuk menghubungkan komputer melalui line kabel dari penyedia jasa telekomunikasi lainnya.

3. Router/Server: merupakan pusat pengendali yang berfungsi sebagai manajemen sistem jaringan di SMK Al-Madani Pontianak.

4. Switch: merupakan penghubung komputer-komputer khususnya di SMK Al-Madani Pontianak.

5. Client: merupakan komputer pengguna, dalam hal ini adalah komputer Kepala Sekolah, Wakil Kepala Sekolah, dan Staff Tata Usaha.

Skema jaringan komputer di SMK Al-Madani Pontianak memiliki alamat-alamat yang digunakan untuk saling berkomunikasi. Alamat-alamat tersebut dikenal dengan nama IP Address.

Tabel 1. IP Address

\begin{tabular}{|c|c|c|c|c|c|}
\hline No & User & IP Address & Subnetmask & Gateaway & Ruangan \\
\hline 1 & Router & 192.168.11.1 & 255.255 .255 .0 & 192.168 .11 .0 & Laboratorium \\
\hline 2 & PC1 & 192.168.11.2 & 255.255 .255 .0 & 192.168.11.0 & \\
\hline 3 & PC2 & 192.168.11.3 & 255.255 .255 .0 & 192.168.11.0 & Kepala Sekolah \\
\hline 4 & PC3 & 192.168.11.4 & 255.255 .255 .0 & 192.168 .11 .0 & \\
\hline 5 & PC4 & 192.168.11.5 & 255.255 .255 .0 & 192.168.11.0 & \\
\hline 6 & PC 5 & 192.168.11.6 & 255.255 .255 .0 & 192.168.11.0 & Sakn керага \\
\hline 7 & PC 6 & 192.168.11.7 & 255.255 .255 .0 & 192.168.11.0 & \\
\hline 8 & PC 7 & 192.168.11.8 & 255.255 .255 .0 & 192.168.11.0 & \\
\hline 9 & PC 8 & 192.168.11.9 & 255.255 .255 .0 & 192.168.11.0 & Tata Usaha \\
\hline 10 & PC 9 & 192.168.11.10 & 255.255 .255 .0 & 192.168.11.0 & \\
\hline
\end{tabular}

Berdasarkan skema tersebut, proteksi keamanan jaringan selain menggunakan antivirus juga menggunakan firewall filtering dengan menggunakan mikrotik. Berikut tampilan awal mikrotik.

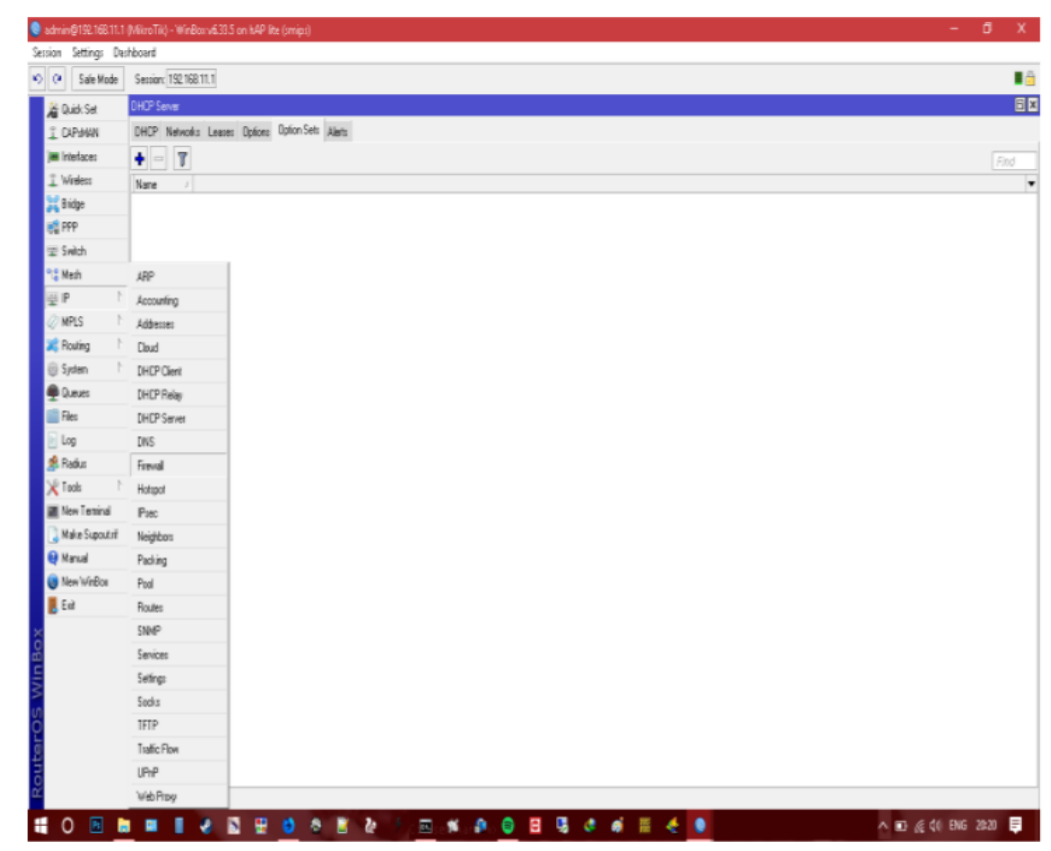

Gambar 2. Mikrotik

Aplikasi mikrotik memiliki pengaturan dalam proteksi jaringan komputer. Salah satu pengaturan yang digunakan dalam mengamankan jaringan di ruang Kepala sekolah, Wakil Kepala Sekolah, dan Tata Usaha yaitu menggunakan firewall. 


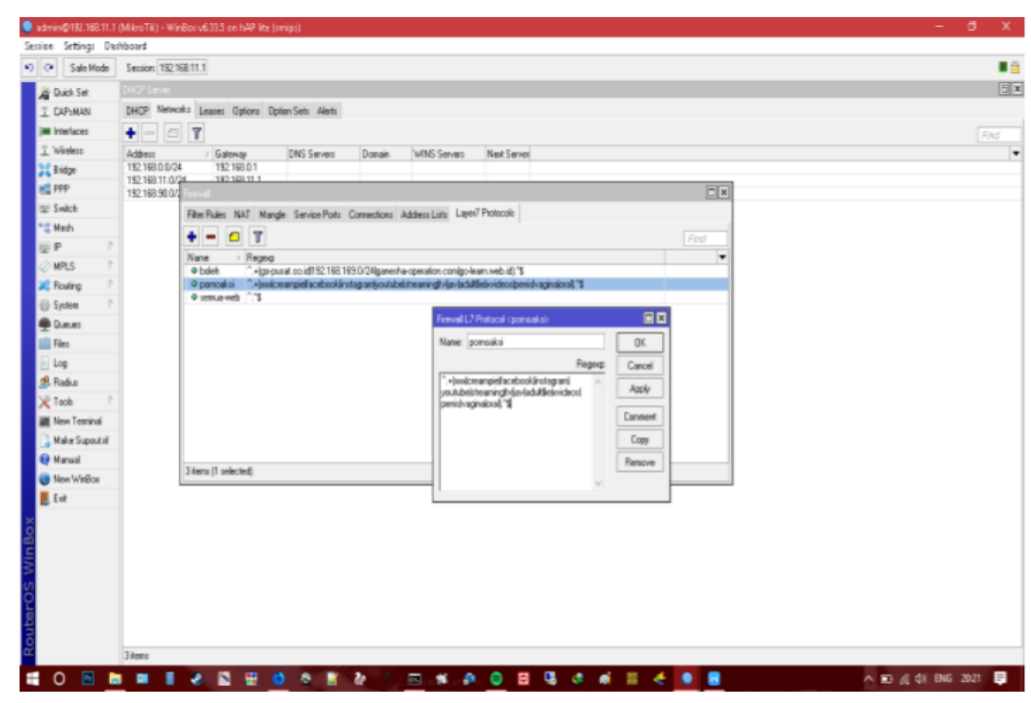

Gambar 3. Pengaturan Firewall

Pengaturan firewall dapat di masukkan rule (aturan) dalam mengamankan jaringan komputer. Dengan menggunakan tanda "+" pada rule firewall yang berisikan tentang keyword yang akan di blok pada sistem keamanan jaringan komputer. Contohnya seperti pada gambar 4.3 "^.+(xxx|facebook|instagram|youtube|).*\$". Arti dari keyword tersebut adalah saat client mengakses situs dari facebook, instagram, atau youtube maka akses tersebut tidak akan diijinkan oleh server.

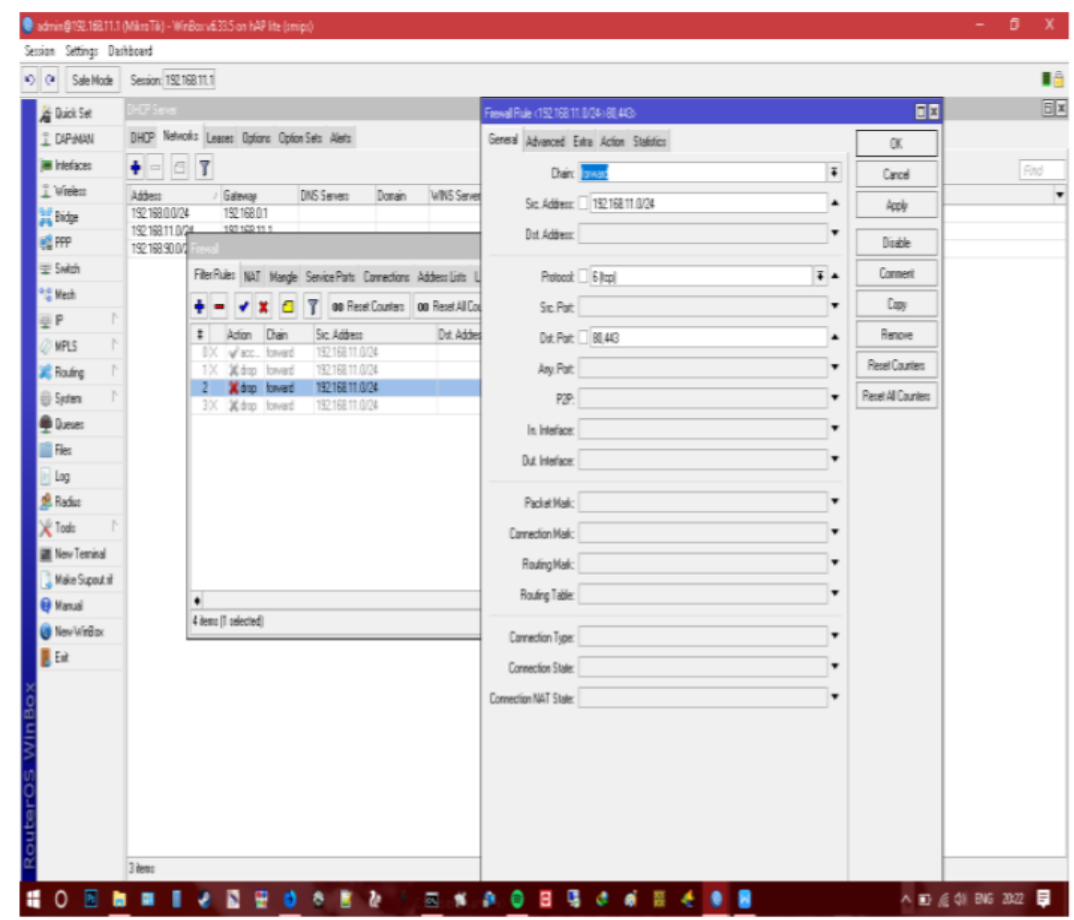

Gambar 4. Pengaturan Firewall Rule

Dalam pengaturan firewall rule, pilih chain forward untuk menandai trafik yang akan menuju router. Dengan cara memilih "IN" dan "OUT" pada pengaturan firewall rule serta memasukkan src address 192.168.11.0/24. Hal ini berfungsi untuk mengubah source address dari paket data. Sehingga mikrotik akan membatasi semua komputer yang memiliki IP Address 192.168.11.0/24. 


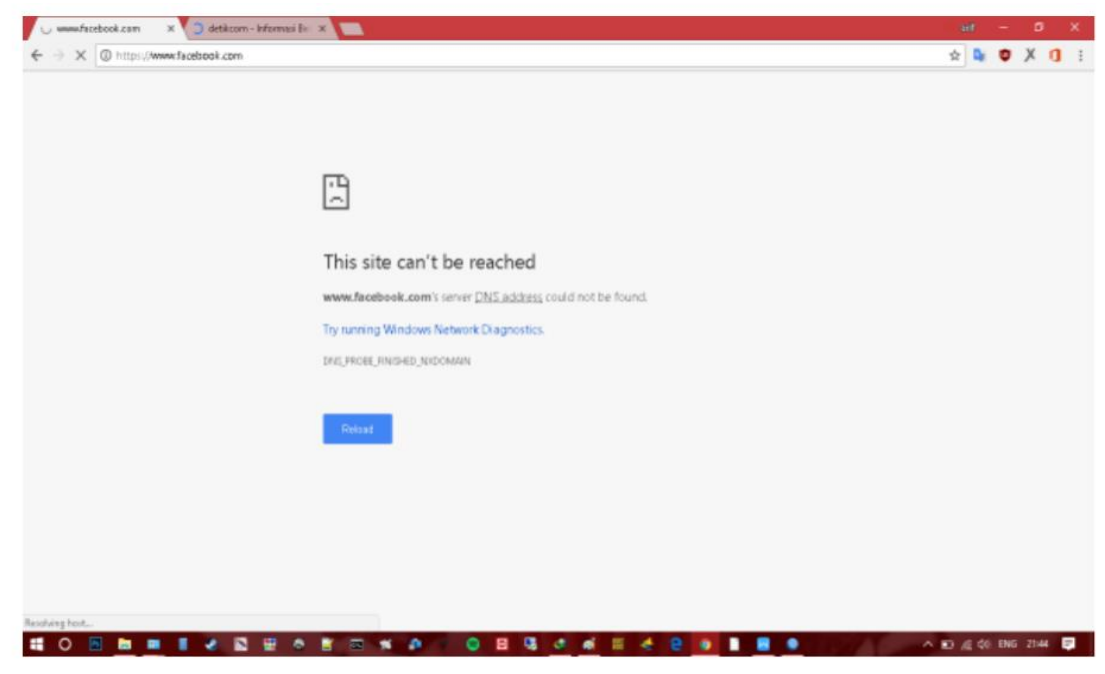

Gambar 5. Tampilan Blok Situs

Gambar tersebut menunjukkan bahwa situs www.facebook.com telah di blok. Saat ada client yang mengakses situs tersebut maka browser akan menampilkan seperti pada gambar 4.5 yang mengartikan "bahwa situs tidak dapat dijangkau"

Sekolah Menengah Kejuruan Al-Madani Pontianak memiliki fasilitas ruangan Kepala Sekolah, ruangan Wakil Kepala Sekolah, ruangan Tata Usaha, ruangan Kelas, ruangan Guru, dan ruangan Laboratorium Komputer. Ruangan-ruangan tersebut dapat saling berkumunikasi dengan menggunakan jaringan komputer. Namun jaringan komputer yang berada di Sekolah Menengah Kejuruan Al-Madani Pontianak memiliki proteksi yang minim. Proteksi yang dimiliki hanya sebatas antivirus, antivirus tersebut tidak dapat memproteksi dari situs-situs yang tidak diijinkan oleh pihak sekolah seperti situs facebook, instagram, dan youtube.

Sekolah Menengah Kejuruan Al-Madani Pontianak k memiliki skema jaringan komputer dengan komponen-komponen seperti: Modem, Router/Server, Switch, dan PC Client. Dimana komponenkomponen tersebut terhubung dalam jaringan yang luas dan mendunia yaitu internet. Kompnen tersebut memiliki IP address yang digunakan agar dapat saling terhubung dan berkomunikasi. IP address setiap komponen tersebut secara berurutan mulai dari 192.168.11.1 hingga 192.168.11.10. Dimana komponen tersebut dihubungan dengan jembatan (gateaway) dengan IP address 192.168.11.0.

IP address yang dimiliki setiap komponen jaringan tersebut diproteksi oleh mikrotik. Dalam hal ini, mikrotik akan mengamankan ruangan Kepala Sekolah, Wakil Kepala Sekolah, dan Tata Usaha. Mikrotik akan memblok atau membatasi beberapa situs yang diatur dan dikendalikan sesuai pihak sekolah. Sebagai contoh, bahwa situs yang di blok yaitu: facebook, instagram, dan youtube. Sehingga jika ruangan kepala sekolah, wakil kepala sekolah, dan tata usaha mencoba mengakses situs tersebut, maka mikrotik akan memblok situs tersebut dan menampilkan informasi bahwa "situs tersebut tidak dapat dijangkau".

Hal tersebut membuktikan bahwa Sekolah Menengah Kejuruan Al-Madani Pontianak telah memiliki proteksi jaringan komputer yang dapat diatur dan dikendalikan sesuai peraturan di Sekolah Menengah Kejuruan Al-Madani Pontianak. Berdasarkan wawancara dengan Kepala Sekolah, dengan adanya proteksi jaringan di Sekolah Menengah Kejuruan Al-Madani Pontianak dapat meningkatkan kinerja karyawan khususnya di Sekolah Menengah Kejuruan Al-Madani Pontianak.

\section{Simpulan dan saran}

Berdasarkan hasil wawancara dan observasi kepada pihak sekolah, maka dapt ditarik kesimpulan bahwa Sekolah Menengah Kejuruan Al-Madani Pontianak memiliki fasilitas ruangan Kepala Sekolah, Wakil Kepala Sekolah, Tata Usaha, Kelas, Guru, dan Laboratorium Komputer. Dimana ruangan ini saling terhubung dengan jaringan komputer. Ruangan Kepala Sekolah, Wakil Kepala Sekolah, dan Tata Usaha memiliki suatu keamanan jaringan dengan menggunakan antivirus. Antivirus yang digunakan tidak dapat membatasi/memblok suatu situs website. Sehingga karyawan SMK Al-Madani dapat mengakases situs tersebut dan dapat menurunkan kinerja. Selanjutanya Sekolah Menengah Kejuruan (SMK) Al-Madani Pontianak memiliki skema jaringan komputer dengan komponen-komponen salah satunya yaitu mikrotik. Mikrotik akan mengamankan ruangan Kepala Sekolah, Wakil Kepala Sekolah, dan Tata Usaha. Mikrotik akan memblok atau membatasi beberapa situs yang diatur dan dikendalikan sesuai pihak sekolah. Sebagai 
contoh, bahwa situs yang di blok yaitu: facebook, instagram, dan youtube. Sehingga jika ruangan kepala sekolah, wakil kepala sekolah, dan tata usaha mencoba mengakses situs tersebut, maka mikrotik akan memblok situs tersebut dan menampilkan informasi bahwa "situs tersebut tidak dapat dijangkau".

Berdasarkan hasil penelitian yang telah dilakukan, maka dapat diajukan saran yaitu: posisi server sebaiknya dipisahkan dengan laboratorium komputer. Karena suhu ruangan server rata-rata 20-250C, kelembaban ruangan sekitar 40\%-55\%, dan kebersihan ruangan menjadi salah satu faktor. Karena debu dapat menyebabkan pendingin menjadi tidak efektif dan membuat server cepat panas (overheating).

\section{Daftar Rujukan}

Arikunto, S., 2006. Prosedur Penelitian Suatu Pendekatan Praktik. Jakarta: Rineka Cipta.

Alexander Pandu Baskoro. (2011). "Analisis dan Perancangan Jaringan Komputer Studi Kasus: Inna Garuda Yogyakarta". Tugs AkhirProram Studi Teknik Informatika Universitas Atma Jaya Yogyakarta.

Basrowi \& Suwandi. 2008. Prosedur Penelitian Tindakan Kelas. Bogor: Ghalia Indonesia.

Budi, R. (1999). "Keamanan Sistem Informasi Berbasis Internet". PT. Insan Komunikasi Indonesia. Bandung.

David, I. (1997). "An Analysis Of Security Incidents On The Internet 1989-1995” Enginering and Public Policy, Carnegia Mellon University. Tesis.

Fadlil., A, Riadi, I, dan Aji, S. (2017). “Pengambangan Sistem Pengaman Jaringan KOmputer Berdasarkan Analisis Forensik Jaringan". Jurnal Ilmu Teknik Elektro KOmputer dan Informatikan. Vol. 3. No. 1.

Meylan Anggara, Yesi Novaria Kunang. (2013). "Analisis dan Arsitektur Desain Jaringan Komputer SMA Negeri 1 Muara Enim". Tugas Akhir Jurusan Teknik Informatika Universitas Bina Darma, Palembang.

Muhammad Nur Ikhsanto, Handoyo Widi Nugroho. (2015). "Analisa Performa dan Desain Jaringan Kompute Menggunakan Top - Down Network Desain Studi Kasus pada CV. Merah Putih". Jurnal TIM Darmajaya Vol.01 no 01. Mei 2015. ISSN: 2442 - 5567.

Randy M, dkk. (2015). Perancangan dan Analisis Keamanan Jaringan Nirkabel Menggunakan Wireless Instruction Detection System. E-journal Teknik Elektro dan Komputer Vol.5. No.7. ISSN.2301-8402.

Riyanto, Umi Fadlilah, Muhammad Kusban. (2013). "Analisis dan Perancangan Kemanan Jaringan Kabel dan Nirkabel pada Kantor Imigrasi Kelas II Kabupaten Karawang". Tugas Akhir Program Studi Teknik Informatika Universitas Muhammadiyah Surakarta: Surakarta.

Singarimbun, Masir, dan Efendi S. 1989. Metode Penelitian Survei. Jakarta: LP3S.

Soeratno, 1995. Metodologi Penelitian. Yogyakarta: UUP AMP YKPN

Tanenbaum, Andrew.S. (1997). “Jaringan Komputer”. Jilid 1. Prenhallindo. Jakarta

Williams, Brian.K. (2003). "Using Information Technology: A Practical Introduction to Computers and Communications". McGrawHilll.NY.

Winarno Sugeng, Indah Septiem Mery. (2012). “Analisis Jaringan Komputer Dinas Komunikasi dan Informatika". Jurnal Informatika No. 1, Vol 3, Januari - April 2012. 